\title{
Adenosine A2a receptor agonist CGS21680 treatment attenuates cardiopulmonary bypass-associated inflammatory lung injury in juvenile rats
}

\author{
XIANG KONG, YI ZUO, YU'ANG HUANG and JIANJUN GE \\ Department of Cardiovascular Surgery, The First Affiliated Hospital of USTC, Division of Life Sciences \\ and Medicine, University of Science and Technology of China (USTC), Hefei, Anhui 230001, P.R. China
}

Received October 6, 2018; Accepted April 16, 2019

DOI: $10.3892 / \mathrm{mmr} .2019 .10235$

\begin{abstract}
The adenosine A2a receptor agonist CGS21680 has been suggested to act as an anti-inflammatory agent that protects against cardiopulmonary bypass (CPB)-induced organ injury. However, the therapeutic effects of CGS21680 for CPB-induced lung injury have not been comprehensively evaluated. Using a juvenile rat model, the present study was designed to evaluated whether CGS21680 attenuates CPB-induced lung injury. Our juvenile rat CPB model was established by $60 \mathrm{~min}$ CPB with or without CGS21680 pretreatment (100 $\mu \mathrm{g} / \mathrm{kg}$, in the CPB priming solution). Rats in the Sham group only underwent cannulation and heparinization. Serum and pulmonary levels of inflammatory markers and histological features of pulmonary tissues were analyzed. All juvenile rats survived following CPB. Significantly elevated serum levels of tumor necrosis factor- $\alpha$ (TNF- $\alpha)$, myeloperoxidase (MPO) and interleukin-1 $\beta$ (IL-1 $\beta$ ), and decreased glutathione peroxidase (GSH-PX) levels were observed in the CPB group compared to the Sham group (all $\mathrm{P}<0.05$ ). TNF- $\alpha$, MPO and IL-1 $\beta$ were significantly decreased, while GSH-PX was markedly increased in the CGS group when compared to the CPB group. Consistently, pulmonary tissues from rats in the CPB group showed considerable amounts of damaged pneumocytes, severe edema, and increased alveolar macrophages, and significantly higher lung injury scores compared to the controls. Collectively, these changes were all further attenuated by CGS21680. Pretreatment with CGS21680 before CPB attenuated pulmonary injury, which may be related to the anti-inflammatory effects of CGS21680 downstream of A2a receptor activation.
\end{abstract}

Correspondence to: Dr Jianjun Ge, Department of Cardiovascular Surgery, The First Affiliated Hospital of USTC, Division of Life Sciences and Medicine, University of Science and Technology of China (USTC), 17 Lujiang Road, Hefei, Anhui 230001, P.R. China E-mail: ox999@163.com

Key words: adenosine A2a receptor agonist, cardiopulmonary bypass, inflammation, pulmonary injury

\section{Introduction}

Individuals, particularly children, undergoing cardiac surgery with cardiopulmonary bypass (CPB) may suffer from severe organ injury (1-3). Indeed, CPB induces an inflammatory response that can cause many serious complications, including renal failure, liver dysfunction, acute respiratory distress syndrome (ARDS) and systemic inflammatory response syndrome (SIRS). Among these fatal comorbidities, respiratory disorders are one of the most frequent and severe complications following CPB (4). Therefore, preventative strategies to mitigate the pathogenesis of CPB-induced pulmonary disorders are important for improving the prognosis of patients undergoing CPB-related cardiac surgeries.

Many potential pathways have been suggested to underlie CPB-induced pathogenesis of inflammatory pulmonary injury. Previous studies indicate that adenosine and its agonists exert an anti-inflammatory response, which may potentially be used as a preventative strategy to attenuate CPB-related organ injury $(5,6)$. Adenosine receptors, including four G-protein-coupled receptor isoforms (A1, A2a, A2b and A3), are widely distributed in the nervous, cardiovascular and respiratory systems, as well as in other tissues. The A2a receptor is predominantly expressed in inflammatory cells. Increased intracellular cyclic adenosine monophosphate (cAMP) levels activate the A2a receptor, which subsequently inhibits activation of inflammatory cells and the production and release of plasma inflammation markers, thereby exerting an anti-inflammatory effect (7). Indeed, a previous study by Ohta et al (8) showed that the A2a receptor had a non-redundant role in attenuating inflammation and tissue damage in vivo. Moreover, activation of the A2a receptor has been demonstrated to reduce the recruitment and adhesion of polymorphonuclear neutrophils to pulmonary endothelial cells in vitro (9).

In a pilot study, activation of the A2a receptor with agonist ATL313 attenuated lung injury following CPB in adult rats (6). However, the potential protective role of A2a receptor activation against CPB-induced pulmonary injury, particularly in juveniles, has not been comprehensively evaluated. Investigating the protective mechanisms of A2a receptor activation against CPB-induced lung injury in 
juveniles is of particular significance as the inflammatory response induced by $\mathrm{CPB}$ in children is likely different than the response in adults (10). Therefore, in the present study, a juvenile rat model of CPB was utilized to determine whether the A2a receptor agonist CGS21680 [2-[4-(2-p-carboxyethyl) phenylamino]-5'-N-ethylcarboxamidoadenosine] attenuates CPB-induced lung injury.

\section{Materials and methods}

Animal care. In total, 36 male juvenile Wistar rats (age, 6 weeks; weight, $176.66 \pm 8.57 \mathrm{~g}$ ) were obtained from The Experimental Animal Center of Anhui Medical University. Animals received standard laboratory chow and water ad libitum. Rats were housed in standard stainless steel cages at a constant-temperature $\left(22^{\circ} \mathrm{C}\right)$ and humidity $(55 \%)$ under a 12-h light/dark cycle (lights on from 7:30 a.m. to 7:30 p.m.). All animals received humane care in compliance with the 'Guide for the Care and Use of Laboratory Animals' prepared by the National Institutes of Health (NIH; Bethesda, MD, USA). Study approval was obtained from the Anhui Medical University Ethics Committee (Hefei, China) prior to initiating the study.

Experimental design. Juvenile rats were randomly divided into three groups with 12 animals per group: The Sham group (underwent heparinization and cannulation only); the CPB group (underwent 60 min of CPB with normal priming solution); and the CGS group (underwent $60 \mathrm{~min}$ of CPB with CGS21680 added to the normal priming solution prior to the initiation of $\mathrm{CPB})$.

Surgical procedures. The juvenile rat model of CPB was established as previously described by Dong et al (11) for adult rats. Briefly, juvenile rats were anesthetized via intraperitoneal administration of $3 \%$ sodium pentobarbital $(50 \mathrm{mg} / \mathrm{kg})$. After achievement of adequate anesthesia, the right femoral artery was identified through a $1.5-\mathrm{cm}$ groin incision and cannulated with a 24-gauge intravenous catheter (BD Biosciences, Franklin Lakes, NJ, USA) to serve as the artery inflow cannula. For the left femoral artery, cannulation with a 24-gauge intravenous catheter was used to measure mean arterial pressure (MAP) and obtain blood for arterial blood gas analysis (i-STAT; Abbott Point of Care, Princeton, NJ, USA). A modified 20-gauge multi-orifice intravenous catheter (BD Biosciences) was inserted into the right internal jugular vein and gently placed into the right atrium. Heparin $(3 \mathrm{mg} / \mathrm{kg})$ was administered via the venous cannula to maintain activated clotting times (ACT) $(\sim 480 \mathrm{sec})$.

CPB circuit. The CPB circuit included a sterile $20-\mathrm{ml}$ venous reservoir, a hollow-fiber membrane oxygenator, a roller pump (BT100-2J; Longer Pump, Baoding, China), a silicon tubing with an inner diameter of $1.6 \mathrm{~mm}$ for the arterial line to monitor blood pressure during $\mathrm{CPB}$, and a specially designed tubing to connect the CPB circuit. For the CPB group, the circuit was assembled and primed with $12 \mathrm{ml}$ whole blood obtained from 2 heparinized ( $3 \mathrm{mg} / \mathrm{kg}$ ) donor rats, $3 \mathrm{ml}$ hydroxyethyl starch, $3 \mathrm{ml}$ Ringer's lactate solution, $1 \mathrm{ml}$ mannitol and $1 \mathrm{ml}$ sodium bicarbonate. For the CGS group, CGS21680 (Tocris
Bioscience, Bristol, UK) was added to the priming solution at a dosage of $100 \mu \mathrm{g} / \mathrm{kg}$. We determined this dose based on previous reports which showed that $100 \mu \mathrm{g} / \mathrm{kg}$ CGS21680 attenuated oxidative organ injury related to ischemia, which was consistent with the hypothesized effect of CGS21680 in this study (12). Moreover, our preliminary experiments with $200 \mu \mathrm{g} / \mathrm{kg}$ CGS21680 resulted in excessive mortality in juvenile rats. Based on the literature and our observations, we chose to use $100 \mu \mathrm{g} / \mathrm{kg}$ CGS21680 in the present study. After cannulation and heparinization, juvenile rats were connected to the CPB circuit (Fig. 1). The flow rate was slowly adjusted to maintain a mean blood pressure of $70 \mathrm{mmHg}$. After reaching a final flow rate of $100 \mathrm{ml} / \mathrm{kg} / \mathrm{min}$, the CPB procedure was maintained for $60 \mathrm{~min}$. Gas flow to the oxygenator, which consisted of $100 \% \mathrm{O}_{2}$, was set at $1 \mathrm{l} / \mathrm{h}$ to sustain normal values of arterial blood gases and potential of hydrogen (PH). At the end of the $\mathrm{CPB}$, blood flow was slowly reduced. When all animals were separated from the CPB circuit, the rats were mechanically ventilated and monitored for 60 min post-operatively.

Physiologic data and sample collection. MAP and arterial blood gas were monitored during the pre-, intra- and post-operative periods. Blood samples were collected from the left femoral artery in each group at baseline, 30 and $60 \mathrm{~min}$ during $\mathrm{CPB}$, and $60 \mathrm{~min}$ after the cessation of $\mathrm{CPB}$. Plasma was collected by centrifugation at $1,600 \mathrm{x}$ g for $20 \mathrm{~min}$. The plasma was stored at $-80^{\circ} \mathrm{C}$, which was subsequently used to determine levels of interleukin (IL)- $1 \beta$ and glutathione peroxidase (GSH-PX). The chest was opened after surgery, and the lung was isolated and divided into two parts. One part was stored at $-80^{\circ} \mathrm{C}$ for tumor necrosis factor- $\alpha$ (TNF- $\alpha$ ) and myeloperoxidase (MPO) analyses. The remaining lung was fixed in a $4 \%$ formaldehyde solution for histological observations. Moreover, lung injury severity was quantitatively evaluated according to the number of macrophages, the amount of interstitial infiltrate, and the presence of alveolar edema as previously indicated (13).

Cytokine assays. Plasma levels of IL-1 $1 \beta$ and lung tissue TNF- $\alpha$ levels were assessed using enzyme-linked immunosorbent assay (ELISA) kits specific for rats according to the manufacturer's instructions (Shanghai Crystal Day Biotech Co., Ltd., Shanghai, China).

MPO assay. MPO lung expression, used as an index of tissue neutrophil accumulation and sequestration, was determined using an MPO enzyme-linked immunosorbent assay (ELISA) kit (Nanjing Jiancheng Biological Product, Nanjing, China). MPO activity in lung tissue was expressed as U/g protein.

GSH-PX assay. GSH-PX activity in the plasma was measured using both hydrogen peroxide and tert-butyl hydroperoxide as substrates (Nanjing Jiancheng Biological Product). Plasma GSH-PX activity was expressed as unit of enzyme activity.

Histologic analysis. Pulmonary tissue fixed in $4 \%$ formaldehyde was processed and paraffin embedded. Tissue sections $(5-\mu \mathrm{m})$ were then stained with hematoxylin and eosin (H\&E) and examined under a light microscope. Histological sections were evaluated by an experienced pathologist blinded to the treatment. 


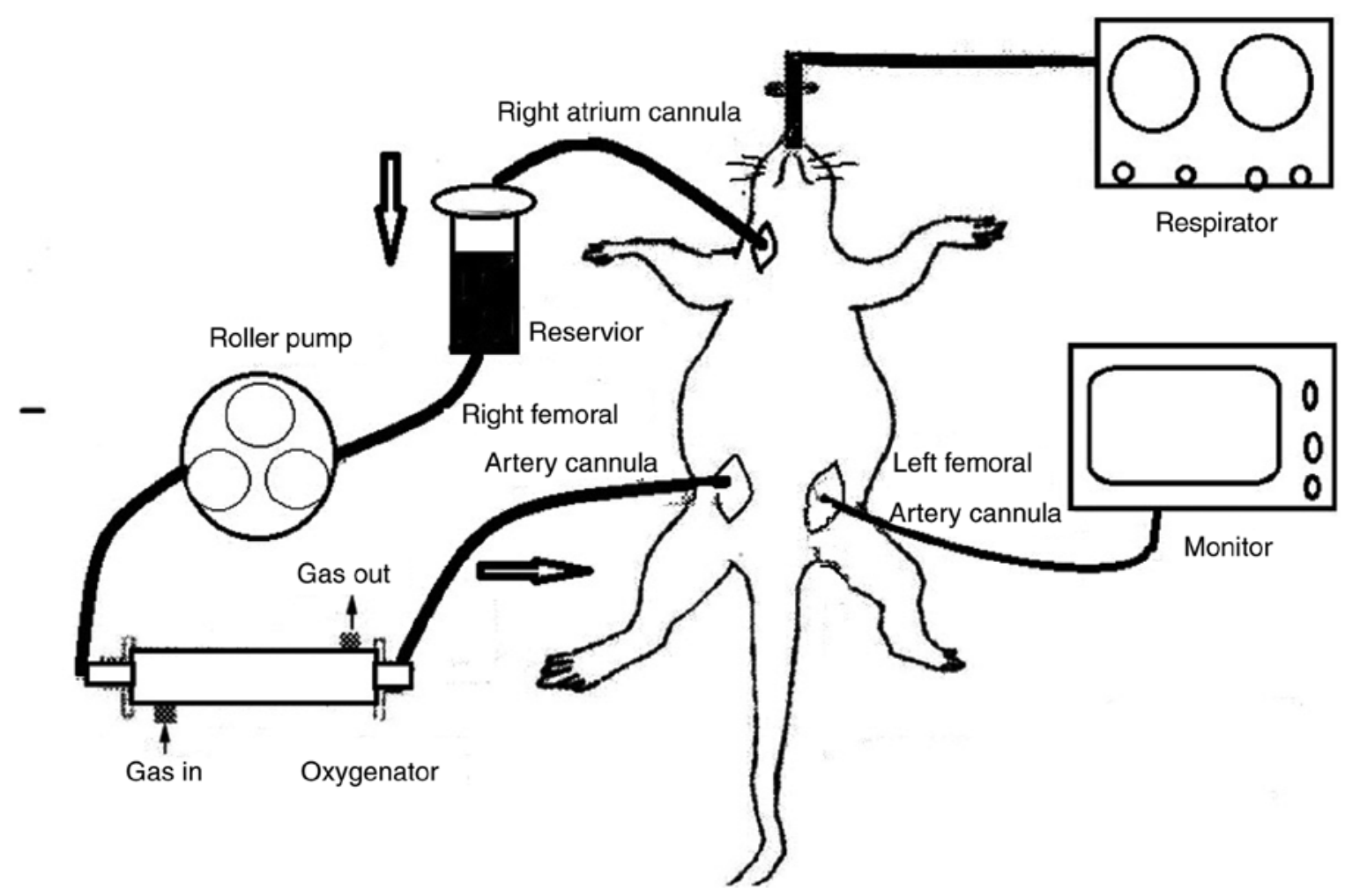

Figure 1. Images of the rat CPB circuit and surgical cannulation. CPB, cardiopulmonary bypass.
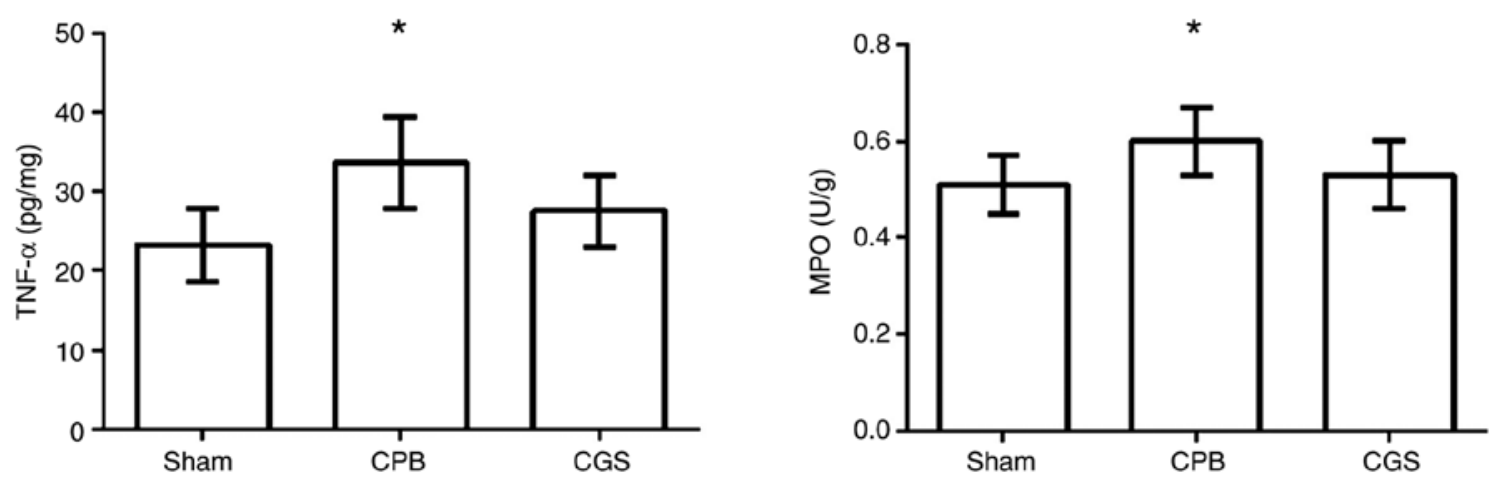

Figure 2. TNF- $\alpha(\mu \mathrm{g} / \mathrm{l})$ and MPO (U/g) levels in pulmonary tissues in each group. ${ }^{*} \mathrm{P}<0.05$ vs. Sham and CGS group. Groups: Sham group (n=12) (underwent heparinization and cannulation only); the CPB group ( $\mathrm{n}=12$ ) (underwent $60 \mathrm{~min}$ of $\mathrm{CPB}$ with normal priming solution); and the CGS group ( $\mathrm{n}=12$ ) (underwent $60 \mathrm{~min}$ of CPB with CGS21680 added to the normal priming solution prior to the initiation of CPB). TNF- $\alpha$, tumor necrosis factor- $\alpha$; MPO, myeloperoxidase; $\mathrm{CPB}$, cardiopulmonary bypass.

Statistical analysis. Continuous values are expressed as mean \pm standard deviation (SD). The SPSS statistics software package (version 17.0; SPSS, Inc., Chicago, IL, USA) was used for data analysis. One-way analysis of variance (ANOVA) was used to determine whether significant differences existed among the three groups. The post hoc test used with ANOVA was Student-Newman-Keuls (SNK) method. A P-value $<0.05$ was considered to indicate a statistically significant result.

\section{Results}

Physiological data. Surgery was successfully completed in all rats, and all rats survived the CPB procedure. Physiological parameters, including blood pressure, oxygen status, carbon dioxide status, hemoglobulin, and serum electrolytes, measured during the pre-, intra- and post-operation time-points are shown in Table I. In our animal model, all physiological parameters remained stable during $\mathrm{CPB}$, which indicates the potential safety of CGS21680 pretreatment. Moreover, our CPB juvenile rat model appeared to be consistent with clinical CPB in children.

TNF- $\alpha$ and MPO levels in lung tissues. We observed a significant increase in TNF- $\alpha$ and MPO levels in the lung tissues in the CPB group compared to the Sham group. However, CGS21680 pretreatment significantly reduced the TNF- $\alpha$ and MPO levels (Table II and Fig. 2), indicating a potential anti-inflammatory effect of CGS21680. 
Table I. Physiological data from juvenile rats undergoing CPB.

\begin{tabular}{|c|c|c|c|c|}
\hline Physiological parameters & Baseline & CPB (30 min) & $\mathrm{CPB}(60 \mathrm{~min})$ & Post-CPB $(60 \mathrm{~min})$ \\
\hline \multicolumn{5}{|l|}{ MAP (mmHg) } \\
\hline Sham & $85 \pm 5.8$ & $85 \pm 8$ & $84 \pm 6$ & $85 \pm 6.8$ \\
\hline $\mathrm{CPB}$ & $85 \pm 6.8$ & $72 \pm 12.6$ & $71 \pm 11.3$ & $67 \pm 13.2$ \\
\hline CGS & $84 \pm 5.1$ & $66 \pm 9.6$ & $61 \pm 18.7$ & $60 \pm 9.8$ \\
\hline \multicolumn{5}{|l|}{$\mathrm{Hb}(\mathrm{g} / \mathrm{dl})$} \\
\hline Sham & $11.7 \pm 1.68$ & $11.8 \pm 1.78$ & $11.7 \pm 1.76$ & $11.6 \pm 1.79$ \\
\hline $\mathrm{CPB}$ & $11.6 \pm 1.83$ & $6.5 \pm 0.78$ & $6.5 \pm 0.7$ & $6.3 \pm 0.91$ \\
\hline CGS & $11.9 \pm 1.89$ & $7.7 \pm 0.92$ & $7.4 \pm 0.87$ & $6.9 \pm 1.16$ \\
\hline \multicolumn{5}{|l|}{$\mathrm{PaO}_{2}(\mathrm{mmHg})$} \\
\hline Sham & $85.1 \pm 6.93$ & $86.2 \pm 7.96$ & $85.4 \pm 5.92$ & $84.6 \pm 4.76$ \\
\hline $\mathrm{CPB}$ & $85.7 \pm 6.72$ & $328 \pm 54.65$ & $331.5 \pm 52.68$ & $320 \pm 64.16$ \\
\hline CGS & $86 \pm 7.57$ & $334.1 \pm 40.84$ & $328.8 \pm 43.05$ & $318.3 \pm 55.52$ \\
\hline \multicolumn{5}{|l|}{$\mathrm{Na}(\mathrm{mmol} / \mathrm{l})$} \\
\hline Sham & $130.6 \pm 2.35$ & $131.3 \pm 2.34$ & $130.9 \pm 5.57$ & $130.3 \pm 2.77$ \\
\hline $\mathrm{CPB}$ & $130.9 \pm 3$ & $131.4 \pm 3.15$ & $130.5 \pm 2.94$ & $130.4 \pm 2.50$ \\
\hline CGS & $130.8 \pm 2.29$ & $130.8 \pm 2.73$ & $131.4 \pm 2.81$ & $131.8 \pm 3.01$ \\
\hline \multicolumn{5}{|l|}{$\mathrm{K}(\mathrm{mmol} / \mathrm{l})$} \\
\hline Sham & $4.3 \pm 0.35$ & $4.2 \pm 0.38$ & $4.3 \pm 0.33$ & $4.3 \pm 0.36$ \\
\hline $\mathrm{CPB}$ & $4.4 \pm 0.47$ & $4.2 \pm 0.44$ & $4.3 \pm 0.42$ & $4.3 \pm 0.42$ \\
\hline CGS & $4.4 \pm 0.39$ & $4.2 \pm 0.37$ & $4.3 \pm 0.36$ & $4.1 \pm 0.36$ \\
\hline
\end{tabular}

Values are represented as means \pm standard errors. Groups: Sham group $(\mathrm{n}=12)$ (underwent heparinization and cannulation only); the CPB group ( $n=12$ ) (underwent 60 min of CPB with normal priming solution); and the CGS group ( $n=12)$ (underwent 60 min of CPB with CGS21680 added to the normal priming solution prior to the initiation of $\mathrm{CPB}$ ). CPB, cardiopulmonary bypass; MAP, mean arterial pressure; Hb, hemoglobin; $\mathrm{PaO}_{2}$, partial pressure of oxygen.

Table II. TNF- $\alpha(\mathrm{pg} / \mathrm{mg})$ and MPO (U/g) levels in lung tissue in each group.

\begin{tabular}{lrrr}
\hline Parameters & Sham group & CPB group & CGS group \\
\hline TNF- $\alpha$ (pg/mg protein) & $23.26 \pm 4.57$ & $33.63 \pm 5.86^{\mathrm{a}}$ & $27.51 \pm 4.51^{\mathrm{b}}$ \\
MPO (U/g protein) & $0.51 \pm 0.06$ & $0.60 \pm 0.07^{\mathrm{a}}$ & $0.53 \pm 0.07^{\mathrm{b}}$
\end{tabular}

Values are presented as means \pm standard errors. ${ }^{\mathrm{a}} \mathrm{P}<0.05$ vs. Sham; ${ }^{\mathrm{b}} \mathrm{P}<0.05$ vs. CPB. Groups: Sham group ( $\mathrm{n}=12$ ) (underwent heparinization and cannulation only); the CPB group ( $\mathrm{n}=12$ ) (underwent $60 \mathrm{~min}$ of $\mathrm{CPB}$ with normal priming solution); and the CGS group ( $\mathrm{n}=12$ ) (underwent 60 min of CPB with CGS21680 added to the normal priming solution prior to the initiation of CPB). TNF- $\alpha$, tumor necrosis factor- $\alpha$; MPO, myeloperoxidase; $\mathrm{CPB}$, cardiopulmonary bypass.

Plasma IL-1 $\beta$ and GSH-PX levels. We observed a significant decrease in plasma GSH-PX in the CPB group compared to the Sham group. CGS21680 treatment largely reversed this effect. Similarly, plasma IL-1 $\beta$ levels in the CPB group were significantly increased compared to the Sham group, which was also reversed by CGS21680 treatment (Table III and Figs. 3 and 4). These results further confirm the anti-inflammatory effect of CGS21680 pretreatment.

Histological results. Our histological analysis demonstrated a considerable amount of damaged pneumocytes, severe edema, and increased alveolar macrophages in pulmonary tissues from the CPB group compared to the Sham group. Moreover, CGS21680 pretreatment significantly attenuated pulmonary inflammatory after CPB, as evidenced by less edema and fewer alveolar macrophages in the CGS21680-treated group (Fig. 5). These results are consistent with the lung injury score differences in each group as presented in Fig. 6.

\section{Discussion}

In the present study, it was confirmed that cardiopulmonary bypass $(\mathrm{CPB})$ is associated with inflammatory lung injury 
Table III. Plasma levels of IL-1 $\beta$ and GSH-PX activity in each group.

\begin{tabular}{lcccc}
\hline Parameters & Baseline & CPB (30 min) & CPB (60 min) & Post-CPB (60 min) \\
\hline IL-1 $\beta$ (ng/l) & & & & \\
Sham & $84.44 \pm 6.89$ & $85.67 \pm 6.06$ & $86.98 \pm 4.95$ & $86.55 \pm 5.08$ \\
CPB & $85.32 \pm 6.69$ & $105.68 \pm 4.99^{\mathrm{a}}$ & $107.33 \pm 4.22^{\mathrm{a}}$ & $108.86 \pm 5.61^{\mathrm{a}}$ \\
CGS & $84.92 \pm 5.74$ & $92.73 \pm 5.98^{\mathrm{b}}$ & $96.10 \pm 5.11^{\mathrm{b}}$ & $97.96 \pm 5.25^{\mathrm{d}}$ \\
GSH-PX (unit of enzyme activity) & & & & \\
Sham & $213.56 \pm 10.93$ & $212.96 \pm 10.34$ & $214.14 \pm 12.65$ & $213.03 \pm 12.77$ \\
CPB & $222.65 \pm 14.46$ & $194.18 \pm 12.11^{\mathrm{a}}$ & $188.95 \pm 13.44^{\mathrm{a}}$ & $186.36 \pm 12.74^{\mathrm{a}}$ \\
CGS & $219.77 \pm 13.79$ & $210.02 \pm 12.20^{\mathrm{b}}$ & $210.00 \pm 11.50^{\mathrm{b}}$ & $206.74 \pm 12.38^{\mathrm{b}}$
\end{tabular}

Values are presented as means \pm standard errors. ${ }^{\mathrm{a}} \mathrm{P}<0.05$ vs. Sham; ${ }^{\mathrm{b}} \mathrm{P}<0.05$ vs. $\mathrm{CPB}$. Groups: Sham group ( $\mathrm{n}=12$ ) (underwent heparinization and cannulation only); the CPB group ( $\mathrm{n}=12$ ) (underwent 60 min of CPB with normal priming solution); and the CGS group ( $\mathrm{n}=12$ ) (underwent 60 min of CPB with CGS21680 added to the normal priming solution prior to the initiation of CPB). CPB, cardiopulmonary bypass; GSH-PX, glutathione peroxidase; IL-1 $\beta$, interleukin- $1 \beta$.

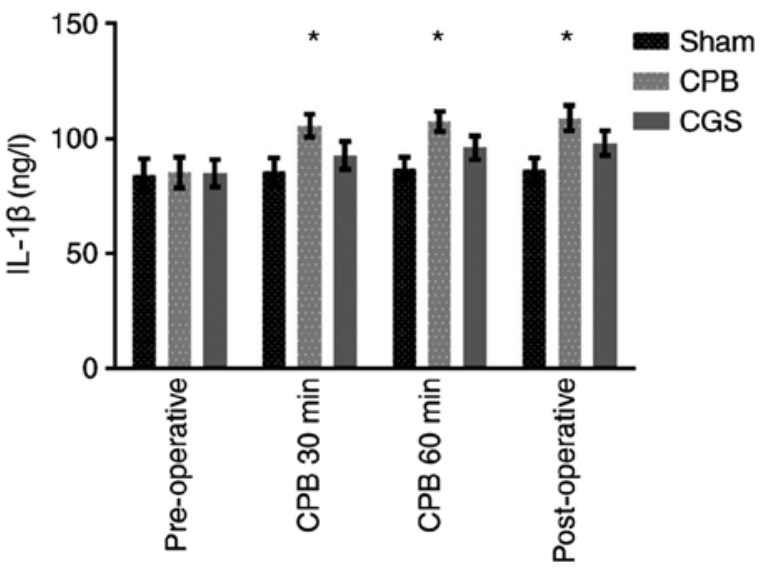

Figure 3. Plasma IL-1 $\beta$ (ng/l) levels in each group. ${ }^{*} \mathrm{P}<0.05$ vs. Sham and CGS group. Groups: Sham group $(\mathrm{n}=12)$ (underwent heparinization and cannulation only); the CPB group ( $\mathrm{n}=12$ ) (underwent 60 min of CPB with normal priming solution); and the CGS group ( $\mathrm{n}=12$ ) (underwent 60 min of CPB with CGS21680 added to the normal priming solution prior to the initiation of CPB). IL, interleukin; CPB, cardiopulmonary bypass.

in juvenile rats. More importantly, it was demonstrated that pretreatment with an adenosine A2a receptor agonist, CGS21680, significantly attenuated inflammatory cell infiltration into the pulmonary tissues following CPB. These anti-inflammatory effects of CGS21680 pretreatment were further evidenced by upregulation of an anti-inflammatory biomarker (GSH-PX) and inhibition of inflammatory cytokines (IL-1 $\beta$, TNF- $\alpha$ and MPO). CGS21680 pretreatment did not significantly affect any physiological parameter during CPB, suggesting the potential safety and feasibility of CGS21680. Taken together, these results demonstrated that CGS21680 pretreatment administered in the CBG priming solution attenuated pulmonary injury in juvenile rats, which supports the use of CGS21680 as a preventative strategy against CPB-induce pulmonary disorders.

CBG can trigger an abundant inflammatory response, as evidenced by platelet activation, increased cytokine production, activated complement and coagulation cascades, and

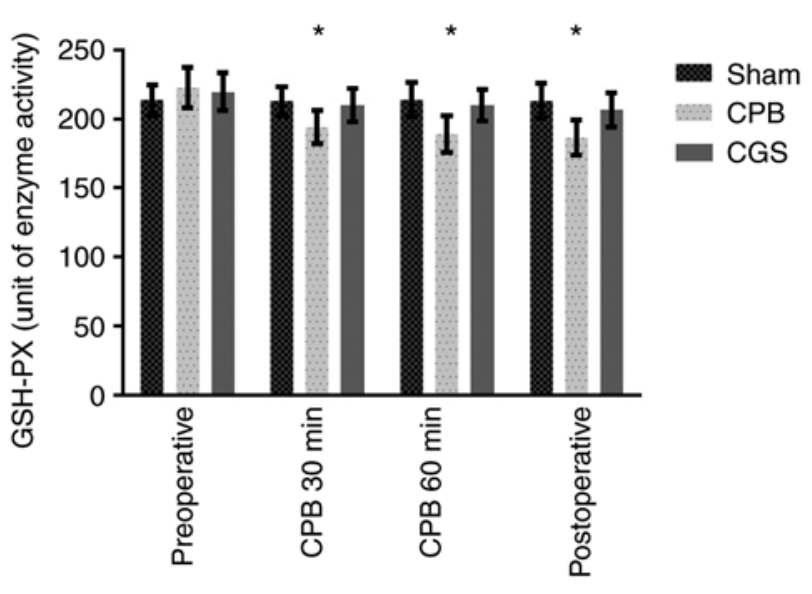

Figure 4. Plasma GSH-PX (unit of enzyme activity) activity in each group. ${ }^{*} \mathrm{P}<0.05$ vs. Sham and CGS group. Groups: sham group $(\mathrm{n}=12)$ (underwent heparinization and cannulation only); the CPB group $(n=12)$ (underwent 60 min of CPB with normal priming solution); and the CGS group $(n=12)$ (underwent $60 \mathrm{~min}$ of CPB with CGS21680 added to the normal priming solution prior to the initiation of $\mathrm{CPB}$ ). CPB, cardiopulmonary bypass; GSH-PX, glutathione peroxidase.

endothelial dysfunction, in both patients and animal models. These changes, in turn, increase susceptibility to various levels of multi-organ dysfunction, including cardiovascular, lung and liver tissues (14-17). The mechanisms underlying the CBP-induced inflammatory response have been investigated $(14,15)$, but still remain unclear. Oxidative/free radicals play an important role in acute lung injury. GSH-PX is an important protective antioxidant against free radicals and other oxidants and has been implicated in attenuating inflammation. An increase in free radicals can be accompanied by a significant decrease in superoxide dismutase and GSH-PX activity (18). Adenosine has been reported to have a strong anti-inflammatory capacity and exert anti-ischemic properties in response to ischemia/reperfusion induced cell injury $(19,20)$. The adenosine A2a receptor subtype is the predominant adenosine receptor expressed on inflammatory cells, and the majority of the anti-inflammatory effects of adenosine may depend on regulation of the A2a receptor (19-21). Therefore, 


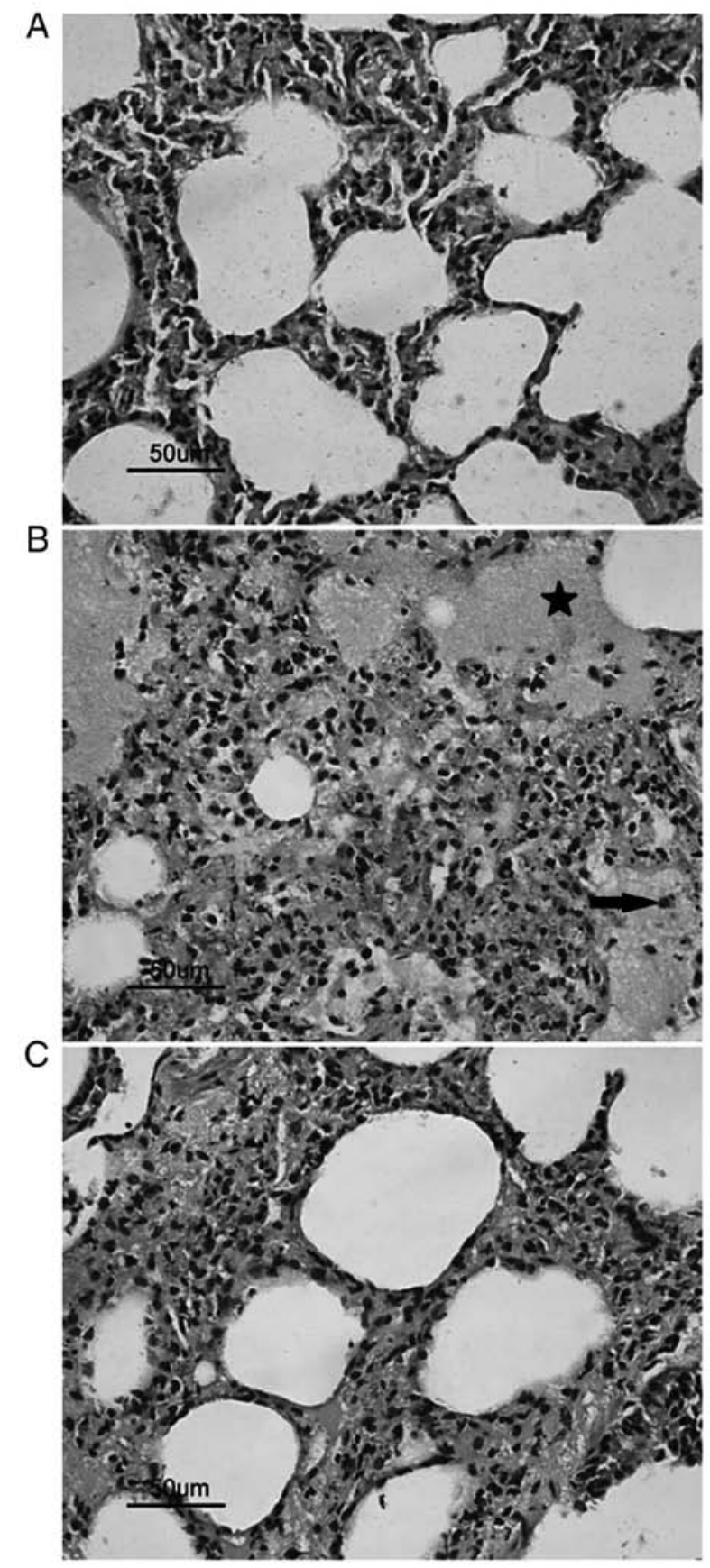

Figure 5. Representative hematoxylin and eosin (H\&E)-stained sections of lung tissues from each group. (A) Lung tissues from the Sham group showed normal pneumocytes adjacent to capillaries without evidence of alveolar macrophages or edema. (B) Lung tissues from the CPB group showed considerable damaged pneumocytes with multiple alveolar macrophages (arrowhead) and significant edema (asterisk). (C) Lung tissues from the CGS group showed few alveolar macrophages and low levels of edema. Groups: sham group $(n=12)$ (underwent heparinization and cannulation only); the $\mathrm{CPB}$ group $(\mathrm{n}=12)$ (underwent $60 \mathrm{~min}$ of $\mathrm{CPB}$ with normal priming solution); and the CGS group ( $\mathrm{n}=12$ ) (underwent $60 \mathrm{~min}$ of CPB with CGS21680 added to the normal priming solution prior to the initiation of $\mathrm{CPB}$ ). $\mathrm{CPB}$, cardiopulmonary bypass. Scale bar, $50 \mu \mathrm{m}$.

we investigated the anti-inflammatory effect of a highly selective adenosine A2a receptor agonist, CGS21680.

The A2a receptor has been identified in nearly all inflammatory cells, including macrophages, eosinophils, neutrophils, endothelial cells, mast cells and T-lymphocytes, and the

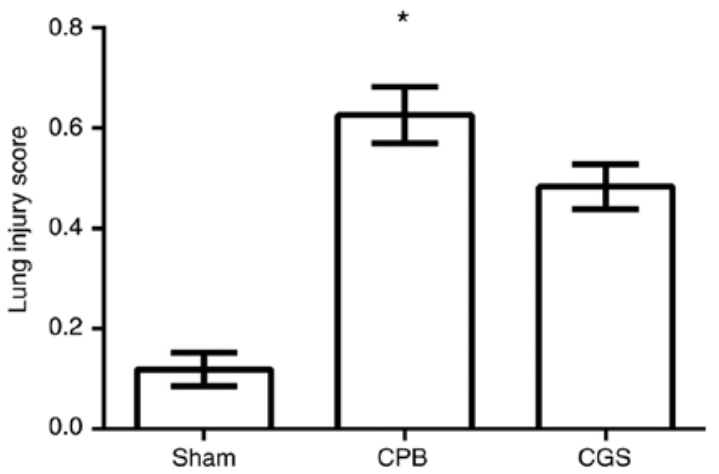

Figure 6. Lung injury score in each group. ${ }^{*} \mathrm{P}<0.05$ vs. Sham and CGS group. Groups: sham group $(n=12)$ (underwent heparinization and cannulation only); the CPB group ( $\mathrm{n}=12$ ) (underwent $60 \mathrm{~min}$ of CPB with normal priming solution); and the CGS group $(n=12)$ (underwent 60 min of $\mathrm{CPB}$ with CGS21680 added to the normal priming solution prior to the initiation of $\mathrm{CPB})$. CPB, cardiopulmonary bypass.

subsequent anti-inflammatory properties of $\mathrm{A} 2 \mathrm{a}$ receptor activation have been shown to inhibit the release of inflammatory mediators, such as interferon, from these cells $(22,23)$. In contrast, A2a receptor agonists have been demonstrated to downregulate the activity of several adhesion molecules, including vascular cell adhesion molecule-1, intracellular adhesion molecule-1, P-selectin and platelet cell adhesion molecule (24-26). Notably, many of these adhesion molecules have been shown to significantly influence the propagation of CPB-induced inflammation (26). At the molecular level, the biological effects triggered by the A2a receptor can increase cAMP production followed by adenylate cyclase activation. The increase in cAMP levels can then stimulate cAMP-dependent kinase, which in turn activates several pathways involving calcium and potassium channels, cAMP responsive element-binding, and phospholipase $\mathrm{C}(27,28)$. These pathways are proposed to collectively inhibit inflammation. However, the exact mechanism by which $\mathrm{A} 2 \mathrm{a}$ receptor activation attenuates the inflammatory response induced by CPB has not been well described. Therefore, more studies should be performed to further elucidate the causal relationship between A2a receptor activation and $\mathrm{CPB}$-induced inflammation.

Clinically, children are more susceptible than adults to CPB-induced inflammatory lung injury. This increased susceptibility is attributed to higher metabolic demands, reactive pulmonary vasculature and immature organ systems in children compared to adults $(16,29)$. Therefore, a juvenile rat model of CPB was utilized in this study, as it has more practical implications. Currently, most investigators use young, large animals, such as sheep, pigs and dogs, in CPB studies. However, most large animals are not inbred pure species, and therefore yield poor reproducibility. There are also other limitations of large animal models, such as inadequate supply of laboratory reagents and incremental research costs. Based on these limitations, we selected juvenile rats for this CPB study, which provided the following advantages. i) The CPB circuit was primed with blood, crystalloid and colloid solutions, which was to some extent consistent with clinical pediatric CPB priming. ii) Successful CPB model establishment in juvenile rats may have direct downstream clinical implications for pediatric researchers. To the best of our 
knowledge, this is the first study to investigate the role of an adenosine $\mathrm{A} 2$ a receptor agonist in $\mathrm{CPB}$-induced inflammatory pulmonary injury in a clinically relevant juvenile rat model. However, the potential prophylactic role of CGS21680 against CPB-induced lung injury in children should be confirmed in clinical trials.

In summary, the present study showed that pretreatment with the adenosine A2a receptor agonist CGS21680 effectively attenuated CPB-induced inflammatory lung injury in a juvenile rat model. Activation of the adenosine A2a receptor with CGS21680 may be a preventative strategy for attenuating inflammatory lung injury during CPB.

\section{Acknowledgements}

Not applicable.

\section{Funding}

The present study was supported by The Anhui Provincial Health Department Foundation of China (grant no. 09B132).

\section{Availability of data and materials}

The datasets used and/or analyzed during the current study are available from the corresponding author on reasonable request.

\section{Authors' contributions}

XK and JG designed the study. XK, YZ, and JG analyzed the data and drafted the manuscript. XK, YZ, and YH prepared the experimental materials and performed the experiments. $\mathrm{XK}$, YZ, and YH interpreted data, performed statistical analysis, and analyzed the results. XK and JG revised the manuscript. All authors read and approved the final version of manuscript and agreed to be accountable for all aspects of the research in insuring that the accuracy and integrity of any part of the work are appropriately investigated and resolved.

\section{Ethics approval and consent to participate}

Ethical approval was obtained from The Anhui Medical University Ethics Committee (Hefei, China).

\section{Patient consent for publication}

Not applicable.

\section{Competing interests}

The authors declare that they have no competing interests.

\section{References}

1. Caputo M, Mokhtari A, Miceli A, Ghorbel MT, Angelini GD, Parry AJ and Suleiman SM: Controlled reoxygenation during cardiopulmonary bypass decreases markers of organ damage, inflammation, and oxidative stress in single-ventricle patients undergoing pediatric heart surgery. J Thorac Cardiovasc Surg 148: 792-801, 2014.
2. Li JA, Liu YL, Liu JP and Li XF: Pulmonary artery perfusion with HTK solution prevents lung injury in infants after cardiopulmonary bypass. Chin Med J (Engl) 123: 2645-2650, 2010.

3. Pappachan VJ, Brown KL and Tibby SM: Paediatric cardiopulmonary bypass surgery: The challenges of heterogeneity and identifying a meaningful endpoint for clinical trials. Intensive Care Med 43: 113-115, 2017.

4. Salameh A, Greimann W, Vollroth M, Dhein S, Bahramsoltani M and Dahnert I: Lung protection in cardio-pulmonary bypass. J Physiol Pharmacol 68: 99-116, 2017.

5. Davidson JA, Urban T, Tong S, Twite M, Woodruff A, Wischmeyer PE and Klawitter J: Alkaline phosphatase, soluble extracellular adenine nucleotides, and adenosine production after infant cardiopulmonary bypass. PLoS One 11: e0158981, 2016.

6. Lisle TC, Gazoni LM, Fernandez LG, Sharma AK, Bellizzi AM, Shifflett GD, Laubach VE and Kron IL: Inflammatory lung injury after cardiopulmonary bypass is attenuated by adenosine $\mathrm{A} 2 \mathrm{~A}$ receptor activation. J Thorac Cardiovasc Surg 136: 1280-1287, 2008.

7. Lappas CM, Sullivan GW and Linden J: Adenosine A2A agonists in development for the treatment of inflammation. Expert Opin Investig Drugs 14: 797-806, 2005.

8. Ohta A and Sitkovsky M: Role of G-protein-coupled adenosine receptors in downregulation of inflammation and protection from tissue damage. Nature 414: 916-920, 2001.

9. Vuorimaa A, Rissanen E and Airas L: In vivo PET imaging of adenosine $2 \mathrm{~A}$ receptors in neuroinflammatory and neurodegenerative disease. Contrast Media Mol Imaging 2017: 6975841, 2017.

10. Jänicke B and Coper $\mathrm{H}$ : The effects of prenatal alcohol exposure on the behavior of rats during their life span. J Gerontol 48: B156-B167, 1993.

11. Dong GH, Xu B, Wang CT, Qian JJ, Liu H, Huang G and Jing H: A rat model of cardiopulmonary bypass with excellent survival. J Surg Res 123: 171-175, 2005.

12. White PJ, Rose'Meyer RB and Hope W: Changes in adenosine receptors mediating hypotension in morphine-dependent rats. Eur J Pharmacol 294: 215-220, 1995.

13. Matute-Bello G, Downey G, Moore BB, Groshong SD, Matthay MA, Slutsky AS and Kuebler WM; Acute Lung Injury in Animals Study Group: An official American Thoracic Society workshop report: Features and measurements of experimental acute lung injury in animals. Am J Respir Cell Mol Biol 44: 725-738, 2011.

14. Chee YR, Watson RW, McCarthy J, Chughtai JZ, Nölke L and Healy DG: High dose statin prophylaxis in cardiopulmonary bypass related surgery: Clinical utility. J Cardiothorac Surg 12: $20,2017$.

15. Fujii Y, Tanabe T, Yamashiro T, Shirai M, Takewa Y and Tatsumi E: Effect of Hydroxyethyl starch priming on the systemic inflammatory response and lung edema after cardiopulmonary bypass in a rat model. ASAIO J 63: 618-623, 2017.

16. Boehne M, Sasse M, Karch A, Dziuba F, Horke A, Kaussen T, Mikolajczyk R, Beerbaum P and Jack T: Systemic inflammatory response syndrome after pediatric congenital heart surgery: Incidence, risk factors, and clinical outcome. J Card Surg 32: 116-125, 2017.

17. Bronicki RA and Hall M: Cardiopulmonary Bypass-induced inflammatory response: Pathophysiology and treatment. Pediatr Crit Care Med 17 (8 Suppl 1): S272-S278, 2016.

18. Nader MA and Baraka HN: Effect of betulinic acid on neutrophil recruitment and inflammatory mediator expression in lipopolysaccharide-induced lung inflammation in rats. Eur J Pharm Sci 46: 106-113, 2012.

19. Sharma AK, LaPar DJ, Stone ML, Zhao Y, Mehta CK, Kron IL and Laubach VE: NOX2 activation of natural killer T cells is blocked by the adenosine A2A receptor to inhibit lung ischemia-reperfusion injury. Am J Respir Crit Care Med 193: 988-999, 2016.

20. Wagner CE, Pope NH, Charles EJ, Huerter ME, Sharma AK, Salmon MD, Carter BT, Stoler MH, Lau CL, Laubach VE and Kron IL: Ex vivo lung perfusion with adenosine A2A receptor agonist allows prolonged cold preservation of lungs donated after cardiac death. J Thorac Cardiovasc Surg 151: 538-545, 2016.

21. Stone ML, Sharma AK, Mas VR, Gehrau RC, Mulloy DP, Zhao Y, Lau CL, Kron IL, Huerter ME and Laubach VE: Ex vivo perfusion with adenosine A2A receptor agonist enhances rehabilitation of murine donor lungs after circulatory death. Transplantation 99: 2494-2503, 2015. 
22. Lappas CM, Rieger JM and Linden J: A2A adenosine receptor induction inhibits IFN-gamma production in murine CD4+ T cells. J Immunol 174: 1073-1080, 2005.

23. Shin EY, Wang L, Zemskova M, Deppen J, Xu K, Strobel F, García AJ, Tirouvanziam R and Levit RD: Adenosine production by biomaterial-supported mesenchymal stromal cells reduces the innate inflammatory response in myocardial ischemia/reperfusion injury. J Am Heart Assoc 7: pii: e006949, 2018.

24. Wang X, Gao M, Schouteden S, Roebroek A, Eggermont K, van Veldhoven PP, Liu G, Peters T, Scharffetter-Kochanek K, Verfaillie CM and Feng Y: Hematopoietic stem/progenitor cells directly contribute to arteriosclerotic progression via integrin $\beta 2$. Stem Cells 33: 1230-1240, 2015.

25. Chhabra P, Linden J, Lobo P, Okusa MD and Brayman KL: The immunosuppressive role of adenosine $\mathrm{A} 2 \mathrm{~A}$ receptors in ischemia reperfusion injury and islet transplantation. Curr Diabetes Rev 8: 419-433, 2012.
26. Hayashi Y, Sawa Y, Nishimura M, Tojo SJ, Fukuyama N, Nakazawa $\mathrm{H}$ and Matsuda $\mathrm{H}$ : P-selectin participates in cardiopulmonary induced inflammatory response in association with nitric oxide and peroxynitrite production. J Thorac Cardiovasc Surg 120: 558-565, 2000.

27. Fredholm BB, Chern Y, Franco R and Sitkovsky M: Aspects of the general biology of adenosine A2A signaling. Prog Neurobiol 83: 263-276, 2007.

28. Ballesteros-Yáñez I, Castillo CA, Merighi S and Gessi S: The role of adenosine receptors in psychostimulant addiction. Front Pharmacol 8: 985, 2018.

29. Kozik DJ and Tweddell JS: Characterizing the inflammatory response to cardiopulmonary bypass in children. Ann Thorac Surg 81 (Suppl): S2347-S2354, 2006. 